\title{
The comparison of protein-entrapped liposomes and lipoparticles: preparation, characterization, and efficacy of cellular uptake
}

This article was published in the following Dove Press journal:

International Journal of Nanomedicine

18 October 2011

Number of times this article has been viewed

\author{
Wei-Kuo Chang' \\ Yu-Ju Tai ${ }^{2}$ \\ Chiao-Hsi Chiang ${ }^{3}$ \\ Chieh-Shen $\mathrm{Hu}^{2}$ \\ Po-Da Hong ${ }^{2}$ \\ Ming-Kung Yeh ${ }^{3,4}$ \\ 'Division of Gastroenterology, \\ Department of Internal Medicine, \\ Tri-Service General Hospital, National \\ Defense Medical Center, Taiwan, ROC; \\ ${ }^{2}$ Graduate Institute of Engineering, \\ National Taiwan University of Science \\ and Technology, Taipei, Taiwan, ROC; \\ ${ }^{3}$ School of Pharmacy, National \\ Defense Medical Center, Taipei, \\ Taiwan, ROC; ${ }^{4}$ Institute of Preventive \\ Medicine, National Defense Medical \\ Center, Sanhsia, Taipei, Taiwan, ROC
}

Correspondence: Ming-Kung Yeh Institute of Preventive Medicine, National Defense Medical Center, PO Box 90048-700, Sanhsia, Taipei 237, Taiwan, ROC

Tel +886 281777038 ext 19896

Fax +886226736954

Email mkyeh2004@gmail.com
Abstract: Fluorescein isothiocyanate-conjugated bovine serum albumin (FITC-BSA)-loaded polyethylene glycol (PEG)-modified liposomes and lipoparticles with high protein entrapment were developed. The lipid formula of the liposomes contained PEGylated lipids and unsaturated fatty acids for enhancing membrane fluidity and effective delivery into cells. The preparation techniques, lipid content, and PEG-modified lipoparticle ratios were evaluated. The PEG-modified lipoparticles prepared by ethanol injection extrusion (100 nm pore size) achieve a population of blank liposomes with a mean size of $125 \pm 2.3 \mathrm{~nm}$ and a zeta potential of $-12.4 \pm 1.5 \mathrm{mV}$. The average particle size of the PEG-modified lipoparticles was $133.7 \pm 8.6 \mathrm{~nm}$ with a zeta potential of $+13.3 \mathrm{mV}$. Lipoparticle conformation was determined using transmission electron microscopy and field-emission scanning electron microscopy. The FITC-BSA encapsulation efficiency was dramatically increased from $19.0 \%$ for liposomes to $59.7 \%$ for lipoparticles Sodium dodecyl sulfate polyacrylamide gel electrophoresis (SDS-PAGE) results confirmed the preparation process, and an 8-hour leaching test did not harm the protein structure. Once prepared, the physical and chemical stability of the PEG-modified lipoparticle formulations was satisfactory over 90 days. In vitro retention tests indicated that the $50 \%$ retention time for the protein-containing lipoparticles was 7.9 hours, substantially longer than the liposomes at 3.3 hours. A Caco- 2 cell model was used for evaluating the cytotoxicity and cell uptake efficiency of the PEG-modified lipoparticles. At a lipid content below $0.25 \mathrm{mM}$, neither the liposomes nor the lipoparticles caused significant cellular cytotoxicity $(P<0.01)$ and FITC-BSA was significantly taken up into cells within 60 minutes $(P<0.01)$.

Keywords: liposomes, lipoparticles, formulation, protein, stability

\section{Introduction}

Liposomes, solid nanoparticles, and many other nanoparticulate carriers have demonstrated biological properties that make them excellent pharmaceutical delivery systems. ${ }^{1-4}$ In particular, liposomes are well recognized as pharmaceutical carriers because of their biocompatibility, biodegradability, and low toxicity and are clinically used for efficacy enhancement and toxicity reduction. ${ }^{5,6}$ Liposomes have good longevity in the blood that allows their accumulation in pathological areas with compromised vasculature, can demonstrate specific targeting to disease sites when various targeting ligands are attached to their surface to enhance intracellular penetration, possess stimulus-sensitivity allowing for drug release from the carriers under certain pathological conditions, and show contrast properties with loading of various contrast materials that allows for direct visualization in vivo..$^{7-9}$ 
Liposomes have been the hallmark of lipid-based nanoparticles for site-specific delivery of drugs and pharmaceuticals. However, Tiwari et a ${ }^{10}$ reported novel gel core liposomes, prepared with bovine serum albumin (BSA), and found these to be an effective tool for immunization. There is a need to develop alternate nanoparticles to improve their stability, and lipid mixtures composed of colloidal assemblies (ie, lipoparticles) are of great interest in biotechnology and biomedicine. This mixture of polymer and lipid-based delivery system contains a core polymer, which serves as a functional skeleton and provides mechanical support to vesicles. It is hoped that these drug carriers may allow for better control over drug release and delivery of therapeutics that do not efficiently load into liposomes. Lipoparticles are stabilized liposomes with all the advantages of liposomes (ie, cell membrane mimicking, targeting, controlled release, and cell-specific interactions), and with increased stability and the added advantage of controlled release over a prolonged period of time. Compared with other drug-delivery systems, lipoparticles have only been developed recently and are potentially attractive and marketable choices due to their natural components and ease of large-scale production. ${ }^{11}$

PEGylated lipoplexes are delivered to cells, but the ability to mediate successful transfection is hampered by their PEGylation. ${ }^{12}$ The potential of formulating dioleoyl trimethylammonium propane (DOTAP)/cholesterol lipoplexes with polyethylene glycol (PEG)-modified lipids would confer the shielding and stabilizing properties of PEG to the particles in the bloodstream. ${ }^{13,14}$ Medium-chain fatty acids (MCFAs; an eight-carbon medium-chain fatty acid) and decanoic acid (a ten-carbon medium-chain fatty acid) have physical and metabolic properties that are distinct from those of long-chain fatty acids that make them a readily available cellular energy source. In animals, MCFAs are absorbed via the portal vein system, which is in contrast to long-chain fatty acids, which are absorbed via the lymphatic system. After incorporation into cells, MCFAs are secreted and transported via the portal vein to the liver. These properties have been used advantageously in clinics for more than 50 years for treating lipid absorption disorders, undernourished patients, and more recently, subjects with long-chain fatty acid oxidation defects. ${ }^{15-17}$

For pharmaceutical development and clinical use, several criteria must be fulfilled in terms of size as well as chemical and physical stability. Small-sized liposomes have several advantages as drug delivery systems. Although designed liposomes can be made by selecting an appropriate composition and production method to achieve a suitable size and size distribution, the effect on drug loading, biodistribution, targeting, therapeutic efficacy, and rate of clearance from the body are of critical importance for in vivo applications of liposomal formulations. ${ }^{18}$ Several techniques have been reported in the literature for liposome preparation. The conventional ethanol injection technique offers the advantage of simplicity, the absence of potentially harmful chemicals, formation of small-sized liposomes without any physical treatments, minimal technical requirements, and the possibility of large-scale production. ${ }^{19,20}$ This is especially true for products based on the ethanol-injection technique that use a membrane contactor module specifically designed for colloidal system preparation, and such scalable liposomal preparation techniques are suitable for the entrapment of pharmaceutical agents into liposomes. ${ }^{21}$

It is known that a homogeneous population of small liposomes represents the best formulation for drug delivery. Thus, from the preparative point of view, we looked for a particular system that was able to reproducibly generate a relatively narrow distribution of small lipoparticles. However, ordinary liposomes exist in liquid form, which leads to several problems resulting in instability, such as particle aggregation/ sedimentation, phospholipid oxidation/decomposition, and drug leakage. Furthermore, the process used for liposome preparation must be reproducible, and the process conditions must allow production at reasonable cost, and economic scale-up. ${ }^{22}$ Therefore, our prepared lipoparticles were freezedried so that these problems could be avoided. ${ }^{23}$

In this paper, we show that lipoparticle drug formulations could be prepared in situ by preparing lipoparticles containing a core of biocompatible protamine with protein within a phospholipid bilayer, in an effort to overcome the limitation of instability and early release of entrapped bioactives. These particles were formed using an ethanol-injection technique, followed by a membrane contactor method optimized by means of various in vitro studies. Several parameters must be optimized in order to obtain a suitable final formulation, and this paper is devoted to such an investigation. Firstly, we studied liposome formulation stability, using the omega-3 fatty acid docosahexaenoic acid (DHA) to modulate membrane fluidity, distearoyl phosphoethanolamine- $\mathrm{PEG}_{2000}$ to improve shielding and stabilizing, as well as the organic and aqueous phases content as a function of the lipid concentration and composition. Products were analyzed by size distribution, as determined by dynamic light scattering and zeta potential. Secondly, by focusing on preparation methods, we showed that it is possible to obtain monomodal size distributions of rather small vesicles. In order to enhance the 
stability of MCFA lipoparticles, strengthen their functional effect, and expand their application domain, lyophilized lipoparticles were prepared, and these could be directly used via injection or aerosol after rehydration. The preparation techniques influenced the size, encapsulation efficiency, and in vitro retention profiles. The optimized formulation was further evaluated for protein structural stability by sodium dodecyl sulfate polyacrylamide gel electrophoresis (SDS-PAGE) and for cell cytotoxicity in Caco-2 cells. We expect that novel lipoparticle carrier systems will have the potential to be applied in drug delivery and clinical therapy to protect the biological activity of proteins and peptides as well as increase efficacy and decrease the occurrence of side effects.

\section{Materials and methods Materials}

Fluorescein isothiocyanate-conjugated bovine serum albumin (FITC-BSA), cholesterol, cis-4,7,10,13,16,19docosahexaenoic acid (DHA), D-(+)-trehalose dihydrate, n-hexane, and protamine sulfate salt from salmon (Grade X), were obtained from Sigma-Aldrich (St Louis, MO). TritonX100 was purchased from Calbiochem-Behring (La Jolla, CA). 1,2-distearoyl-sn-glycero-3-phosphocholine (DSPC) was purchased from Avanti Polar Lipids (Alabaster, AL). N-(carbony-methoxypolyethyleneglycol 2000)-1,2distearoyl-sn-glycero-3-phosphoethanolamine, sodium salt (DSPE-PEG ${ }_{2000}$ ) was purchased from NOF Corporation (Tokyo, Japan). WST-1 cell proliferation reagent was obtained from Clontech Laboratories (Mountain View, CA). Dulbecco's Modified Eagle Medium (DMEM), antibiotic solutions (100 IU/mL penicillin and $100 \mu \mathrm{g} / \mathrm{mL}$ streptomycin), fetal bovine serum (FBS), and phosphate buffer saline (PBS) were supplied by Gibco BRL (Corning, NY). Ultrapure water was obtained with Milli-Q equipment (Millipore, Billerica, MA). All other chemicals and reagents used were of analytical purity or higher quality and obtained commercially.

\section{Preparation of liposomes}

Liposomes were prepared by an ethanol injection method modified from a previous report. ${ }^{12}$ Briefly, varied molar ratios of DSPC/cholesterol/ DSPE-PEG/DHA were melted in a $60^{\circ} \mathrm{C}$ water bath, and the lipid mixture was then dissolved in the proper alcohol solvent and rapidly injected at room temperature with a one-way, $1 \mathrm{~mL}$ syringe into a dispersant water solution. The dispersion was extruded ten times through a polycarbonate membrane (100 nm pore size) using an extruder (Avanti Polar Lipids, Mini-Extruder). The various ratios of lipid content/ethanol/water $(\mathrm{L} / \mathrm{E} / \mathrm{W})$ were evaluated. The total lipid concentration of the prepared liposomes was $0.15 \mathrm{mM}$.

FITC-BSA, if present, was dissolved in the alcohol lipid solution, and the correct aliquot of this solution was injected as described above. Every FITC-BSA-containing preparation was kept in amber glassware to avoid exposure to light. Solutions were always freshly prepared before use.

\section{Preparation of lipoparticles}

Solid cores were prepared using a physical mix method. Briefly, FITC-BSA and protamine sulfate were freshly dissolved in ethanol. The weight ratio of protamine sulfate/ FITC-BSA (20/1) solution was added and mixed. An FITC$\mathrm{BSA} /$ protamine sulfate core was dissolved in the alcohol lipid solution; the correct aliquot of this solution was injected as in the liposome preparation process described above. Untrapped FITC-BSA and protamine sulfate from the lipoparticles were removed by ultracentrifugation at 25,000 $\mathrm{g}$ for 15 minutes (CPMax-100; Hitachi, Tokyo, Japan) and further dialyzed against $800 \mathrm{~mL}$ distilled water for 12 hours at $4^{\circ} \mathrm{C}$ to remove untrapped FITC-BSA from the lipoparticle vesicles.

\section{Preparation of freeze-dried lipoparticles}

D-(+)-trehalose dihydrate was used alone as a cryoprotectant in the lipoparticles, with cryoprotectant and lipoparticles at a ratio of $4: 1(\mathrm{w} / \mathrm{w})$. The lipoparticle suspensions prepared by ethanol injection, with extraction using a $100 \mathrm{~nm}$ membrane, were added to the D-(+)-trehalose dihydrate under optimal conditions and were then filtered using a $0.45 \mu \mathrm{m}$ filter (Millipore, Boston, MA). Using deep-freeze equipment, the lipoparticle suspensions were prefrozen for 6 hours, reaching a terminal temperature of $-80^{\circ} \mathrm{C}$, and then dried at $-86^{\circ} \mathrm{C}$ at $0.1 \mathrm{mbar}$ for 48 hours in a vacuum freeze-drying system. The freeze-dried FITC-BSA-loaded lipoparticles were evaluated in terms of vesicle size, zeta potential, protein stability, and in vitro release.

\section{Size and zeta-potential analysis}

The prepared particles (liposomes or lipoparticles) were diluted to $1 \mathrm{mM}$ using an appropriate volume of sterile PBS ( $\mathrm{pH} 7.3$ ). The weight-average hydrodynamic diameter of the various particles was determined by a dynamic light-scattering method using a particle analyzer (LB-500; Horiba, Tokyo, Japan) at room temperature. Four measurements were performed for each sample. The zeta potential $(\zeta)$ of the particles was measured by determining the 
electrophoretic mobility using a zeta potential analyzer (Zeta Plus; Brookhaven Instruments, Holtsville, NY) at room temperature. Four measurements were performed for each sample.

\section{Morphological investigation}

Particle suspensions were imaged using transmission electron microscopy (TEM) (JSM-1200EXII; JEOL, Tokyo, Japan). A drop of the particle suspension was placed onto a carboncoated copper grid from Ted Pella (Redding, CA), forming a thin liquid film. The films were negatively stained with a $2 \%$ phosphotungstic acid solution (w/w; pH 7.1) for 1 minute. The excess of the phosphotungstic solution was removed with filter paper, and stained samples were characterized using an accelerating voltage of $80 \mathrm{kV}$. The images were examined using a TEM at $75 \mathrm{kV}$. The morphology of the lipoparticles was examined using field emission-scanning electron microscopy (FE-SEM; JSM 6500F; JEOL). The SEM samples were mounted on a carbon adhesive tab and sputter coated $(10-15 \mathrm{~nm})$ with gold palladium (60/40 alloy).

\section{Stability study}

Stability was assessed by comparing changes in mean diameters, zeta potential, and protein activity of one liposome and two lipoparticle formulations. The particle suspension and its freeze-dried powder were stored away from light at $4^{\circ} \mathrm{C}$ for different periods of time. The ability of vesicles to retain protein activity was assessed by varying the preparation process, final product, and release times. At different stages, the samples were withdrawn periodically and analyzed for residual protein activity. Protein integrity was also evaluated by SDS-PAGE.

\section{Standard curve generation}

We prepared a series of $10 \mu \mathrm{L}$ reference solutions that were measured using a fluorometer, and determined the peak areas. The regression equations were then obtained with the content of the FITC-BSA peak area as ordinate. The regression equations were as follows: $\mathrm{y}=0.2654 \mathrm{x}+0.0520, R=0.9998$ for water solution. The results of linearity show that the peak areas were linearly related to the sample concentration within the range of 1.0 and $40 \mu \mathrm{g} / \mathrm{mL} ; \mathrm{y}=2.2473 \mathrm{x}+0.0319$, $R=0.9998$ for the PBS solution; the peak areas were linearly related to the sample concentration within the range of 0.01 and $0.4 \mu \mathrm{g} / \mathrm{mL} ; \mathrm{y}=0.0253 \mathrm{x}+0.0327, R=0.9998$ for the $\mathrm{n}$-hexane extracted solution; and the peak areas were linearly related to the sample concentration within the range of 0.1 and $8.0 \mu \mathrm{g} / \mathrm{mL}$.

\section{Encapsulation efficiency}

Particle encapsulation efficiency was determined based on the amount of entrapped drug (ie, FITC-BSA) using a dialysis method. Dialysis bags were soaked before use in distilled water at room temperature for 12 hours to remove the preservative, followed by rinsing thoroughly in distilled water. Briefly, a volume of the drug-loaded particle sample (V) was loaded in a dialysis device of $1000 \mathrm{kDa}$ molecular weight cutoff (MWCO) (Spectra/Por; Spectrum Laboratories, Rancho Dominguez, CA) with $150 \mathrm{~mL}$ distilled water at $4^{\circ} \mathrm{C}$ in order to separate the unloaded drug. The particles were then dissolved in n-hexane in order to analyze the encapsulated amount of drug (Edrug). The drug encapsulation efficiency (EE\%) was calculated as the percentage of the encapsulated amount (Edrug) relative to the initial theoretical amount (Tdrug), as in the following equation:

$$
\mathrm{EE} \%=(\text { Edrug } / \text { Tdrug }) \times 100
$$

\section{In vitro retention test}

In vitro release of FITC-BSA from the particles was determined using a dialysis device with a $1000 \mathrm{kDa} \mathrm{MWCO}$ in $150 \mathrm{~mL}$ of $\mathrm{PBS}(\mathrm{pH} 7.4)$ at $36^{\circ} \mathrm{C}$ following the method published previously. ${ }^{24}$ Three dialysis devices were prepared containing free FITC-BSA (control), FITC-BSA in liposomes, and FITC-BSA in lipoparticles. An accurately measured amount of various particle formulations was transferred to the dialysis bags and placed in a receiving compartment containing $120 \mathrm{~mL}$ PBS (pH 7.4). Control bags were prepared and tested in parallel. Each control bag contained $0.1 \mathrm{mg}$ FITC-BSA. The two ends of the dialysis bag were tightly bound with thread. The bags were hung inside a conical flask with the help of a glass rod so that the portion of the dialysis bag containing the formulation dipped into the buffer solution. The flask was kept on a magnetic stirrer, and stirring was maintained at $100 \mathrm{rpm}$ at $36^{\circ} \mathrm{C}$ with thermostatic control. At predetermined time intervals the release medium was withdrawn for analysis. By adjusting the concentration of FITC-BSA to the linear range, the amount of released FITC-BSA from the particle was analyzed using a fluorometer. An excitation wavelength of $488 \mathrm{~nm}$ and emission wavelength of $522 \mathrm{~nm}$ were used to observe the fluorescence intensity of FITC-BSA. The FITCBSA retained in the particles was calculated by subtracting the initial amount of FITC-BSA in the particles from the amount at the time of release. To analyze the release kinetics and mechanisms, data were fitted to the three following mathematical models. 
1. Zero order

$$
\mathrm{Mt} / \mathrm{M} \infty=\mathrm{kot}
$$

2. First order

$$
\mathrm{Mt} / \mathrm{M} \infty=1-\exp (-\mathrm{k} 1 \mathrm{t})
$$

3. Higuchi model ${ }^{25}$

$$
\mathrm{Mt} / \mathrm{M} \infty=\mathrm{kh} \mathrm{t} 1 / 2
$$

where $\mathrm{Mt} / \mathrm{M} \infty$ is the fraction of drug released at time $\mathrm{t}$ and $\mathrm{ko}, \mathrm{k} 1$, and $\mathrm{kh}$ represent the zero-order release constant, firstorder release constant, and Higuchi constant, respectively. The constants are related to the structural and geometric characteristic of the device, and are indicative of the drug release mechanism. The values of ko, k1, and kh were determined by fitting the release data into the respective equations.

\section{Protein stability test}

The prepared particles were incubated in PBS for 4 and 8 hours and then analyzed using SDS-PAGE. About $0.1 \mathrm{~mL}$ of $100 \mu \mathrm{g} / \mathrm{mL}$ of protein sample was mixed with $25 \mathrm{~mL}$ of Laemelli's buffer (BioRad, Hercules, CA) and boiled for 5 minutes. The samples were then subjected to electrophoresis at $40 \mathrm{~mA}$ in a vertical slab Ready Gel (12\%; BioRad). Proteins were visualized using a silver staining kit (BioRad). The density of the protein bands in the gel was analyzed using GelExpert software (Nucleotech, San Mateo, CA). The areas of the bands were kept constant for the different gels, and the intensity of the bands was normalized to the background of each gel.

\section{Cell culture}

The established human epithelial colorectal adenocarcinoma cell line Caco-2 was obtained from the American Type Culture Collection (Rockville, MD). Caco-2 cells were routinely grown in cultured DMEM supplemented with 100 $\mathrm{IU} / \mathrm{mL}$ penicillin, $100 \mathrm{mg} / \mathrm{mL}$ streptomycin, $1 \%$ nonessential amino acids, and $20 \%$ fetal bovine serum in $5 \% \mathrm{CO}_{2}$ at $37^{\circ} \mathrm{C}$. The cells were then seeded into flat-bottom 96-well tissue culture plates (Greiner Labortechnik, Frickenhausen, Germany) for cell toxicity assays or into 8-well Lab-Tek II Chamber Slides (Nalge Nunc, Elkhart, IN) for in vitro cellular uptake studies.

\section{In vitro cell viability/cytotoxicity studies}

The effect of the particles on cytotoxicity was evaluated using a commercial colorimetric WST-1 cell proliferation assay (BioChain Institute, Hayward, CA). The WST-1 assay is a simple nonradioactive colorimetric assay for measuring cell cytotoxicity, proliferation, and viability. Aqueous particle suspensions at final concentrations of 2.5, 0.25, 0.025, and $0.0025 \mathrm{mg} / \mathrm{mL}$ were obtained by dispersing the dry particles in water with the aid of an ultrasonicator $\left(40 \mathrm{kHz}, 25^{\circ} \mathrm{C}\right)$. Cells $\left(1.0 \times 10^{5}\right.$ cells $\left./ \mathrm{mL}\right)$ were seeded into 96 -well tissue culture plates in $100 \mu \mathrm{L}$ of culture medium, allowed to adhere for 5 hours, and serum starved in 0.1\% BSA in DMEM for 24 hours prior to use. A total of $5 \mu \mathrm{L}$ of various concentrations of sample were added to each well, and the cells were incubated for 72 hours at $37^{\circ} \mathrm{C}$. Subsequently, $5 \mu \mathrm{L}$ of WST-1 $(5 \mu \mathrm{g} / \mathrm{mL})$ was added to each well for 1 hour at $37^{\circ} \mathrm{C}$ before terminating the incubation. Cells were washed and incubated with $100 \mu \mathrm{L}$ of variously diluted nanoparticles in $0.1 \%$ BSADMEM solution for various times at $37^{\circ} \mathrm{C}$. Absorbance (Abs) was measured at $450 \mathrm{~nm}$ using a spectrophotometer. Cell cytotoxicity was calculated using the following formula: cell cytotoxicity $(\%)=1-[($ Abs of treated cells $) /($ Abs of control untreated cells) $] \times 100$. The viability of cells left untreated was normalized to $100 \%$. Six experimental sets were carried out, and each set was performed in triplicate.

\section{Flow cytometry}

Caco-2 cells were seeded into 8-well plates in DMEM at a cell density of $3 \times 10^{4}$ cells per well and incubated for 24 hours to achieve $75 \%$ confluence. Before the uptake study, the culture media was removed and the cells were washed with PBS. FITC-BSA-loaded particles in $1 \mathrm{~mL}$ of serumfree culture media were then added. At different times, the cells were washed three times with PBS and then detached using $0.05 \%$ trypsin $/ 0.02 \%$ EDTA, washed with PBS, and resuspended in $1 \mathrm{~mL}$ PBS for flow cytometric analysis. The uptake of FITC-BSA-loaded particles was measured using a flow cytometer (FACScan; Becton Dickinson, Heidelberg, Germany). The cells were analyzed using $488 \mathrm{~nm}$ excitation and $522 \mathrm{~nm}$ band-pass filters in the emission path. Forward and side light scatter was used to gate the desired scattered events of normal cells from dead cells and cell debris.

\section{In vitro cellular uptake studies}

It has been shown that the addition of FITC-BSA expresses various integrins and serves as an in vitro cell model for protein delivery. ${ }^{26}$ To determine the delivery efficiency, we determined the uptake of particles by Caco-2 cells. ${ }^{27}$ Briefly, cells were seeded into 8 -well plates at a density of $1 \times 10^{5}$ cells per well in $1 \mathrm{~mL}$ of complete medium and incubated for 24 hours prior to the uptake study. The media was then replaced with fresh growth medium in each well. A total of $200 \mu \mathrm{L}$ of FITC-BSA-loaded particle 
suspensions $(0.01 \mathrm{mg} / \mathrm{mL})$ of different formulations were added to each well, and the plates were incubated again for $60,120,180,240$, and 360 minutes. As a positive control, cell uptake with blank liposomes was performed according to the manufacturer's protocol. All cell uptake experiments were performed in triplicate. The cells were transferred to an inverted fluorescence microscope (DMI 4000B; Leica Microsystems, Wetzlar, Germany) for imaging. Cell uptake efficiency was detected by the analysis of FITC-BSA activity. At different times, the cells were washed three times with PBS and then detached using 0.05\% trypsin/0.02\% EDTA, washed with PBS, and resuspended in $1 \mathrm{~mL}$ of PBS for flow cytometric analysis. The final results were reported in terms of fold increase over the blank liposomes.

\section{Statistical analysis}

Data were expressed as the mean \pm standard deviation (SD), and statistical analysis was carried out employing the Wilcoxon statistics and Student's $t$-test using SPSS software (SPSS, Chicago, IL) to assess the differences between experimental groups. $P<0.05$ was taken as being statistically significant.

\section{Results}

\section{Preparation and characterization of the liposome system}

Stability studies were carried out on drug-free liposome formulations over a period of 28 days. Table 1 shows the effect the ratios of different molar lipids (DSPC/cholesterol/DSPEPEG2000/DHA) and the ratios of lipid, ethanol, and water in the formula had on the particle size and zeta potentials of particles produced by the ethanol injection extrusion method.
The liposome particle size varied between 121 and $157 \mathrm{~nm}$, and the zeta potential varied between -42 and $-30 \mathrm{mV}$. At the same ratios of $\mathrm{L} / \mathrm{E} / \mathrm{W}$, the effects of varied ratios of DSPC/ cholesterol/DSPE-PEG2000 (A vs B; C vs D) were evaluated. The more DSPC in the formula, the smaller the particle size and the less the particle size changed over 28 days. At the same ratios of DSPC/cholesterol/DSPE-PEG2000, the effects of varied ratios of $\mathrm{L} / \mathrm{E} / \mathrm{W}$ (A vs $\mathrm{C}$ ) were evaluated. The higher the lipid content, the smaller the particle size and the less the particle size changed over the 28 days. The lower the lipid content, the closer to neutral the zeta potential was. With a further increase in the ratios of $\mathrm{L} / \mathrm{E} / \mathrm{W}$ from $75 / 1 / 6$ to $75 / 1 / 9$ (E), an increased stability in zeta potential and size was achieved.

Formulations $\mathrm{E}$ and $\mathrm{F}$ were selected in order to follow the variation in vesicle size over 190 days at $4{ }^{\circ} \mathrm{C}$; the mean particle size and zeta potential are presented in Figure 1. As shown in Figure 1, regardless of the change in particle size or zeta potential, the E formulation (Figure 1A) was more stable than the $\mathrm{F}$ formulation (Figure 1B). The liposome size of formula $\mathrm{E}(2-7 \mathrm{~nm})$ remained nearly unchanged over 1 month, as no significant differences were observed over this period. This indicated that after storing for 1 month, separation and stratification did not occur in the aqueous liposome suspensions.

We varied the DHA content (5\%-30\%), replacing DSPC in the formula, and the change in particle size and zeta potential was evaluated in the different formulas: DSPC/cholesterol/DSPE-PEG2000/DHA of E ( $0 \%$ of DHA), E5 (5\% of DHA), E15 (15\% of DHA), and E30 (30\% of DHA). The formula containing $15 \%$ DHA (E15) resulted in the most stable particle size and zeta potential over 28 days. Therefore, we

Table I The stability effect of different lipid molar ratios and L/E/W ratio formulas following the ethanol injection extrusion method

\begin{tabular}{|c|c|c|c|c|c|c|c|c|}
\hline \multirow[t]{2}{*}{ No } & \multirow{2}{*}{$\begin{array}{l}\text { Lipid } \\
\text { molar } \\
\text { ratio }^{a}\end{array}$} & \multirow{2}{*}{$\begin{array}{l}\text { L/E/W } \\
\text { ratio }^{\text {b }}\end{array}$} & \multicolumn{3}{|c|}{ Particle size $(\mathrm{nm})$} & \multicolumn{3}{|c|}{ Zeta potential $(\mathrm{mV})$} \\
\hline & & & $\begin{array}{l}0 \text { (day) } \\
\text { mean } \pm \text { SD } \\
(C V \%)^{c}\end{array}$ & $\begin{array}{l}7 \text { (day) } \\
\text { mean } \pm \text { SD } \\
(\mathrm{CV} \%)\end{array}$ & $\begin{array}{l}28 \text { (day) } \\
\text { mean } \pm \text { SD } \\
(\mathrm{CV} \%)\end{array}$ & $\begin{array}{l}0 \text { (day) } \\
\text { mean } \pm \text { SD } \\
(C V \%)\end{array}$ & $\begin{array}{l}7 \text { (day) } \\
\text { mean } \pm \text { SD } \\
(C V \%)\end{array}$ & $\begin{array}{l}28 \text { (day) } \\
\text { mean } \pm \text { SD } \\
(\mathrm{CV} \%)\end{array}$ \\
\hline A & $59 / 36 / 5 / 0$ & $75 / 1 / 6$ & $|2| \pm 5(4)$ & $12 \mid \pm 7(6)$ & $112 \pm 4(4)$ & $-42.8 \pm 0.7(1.6)$ & $-35.2 \pm 1.2(3.4)^{* \text { *ipk }}$ & $-20.1 \pm 0.7(3.6)^{* * k k}$ \\
\hline B & $39 / 57 / 4 / 0$ & $75 / 1 / 6$ & $|3| \pm 3(3)$ & $110 \pm 6(5)^{* *}$ & $114 \pm 10(9)^{*}$ & $-30.5 \pm 2.3(7.5)$ & $-27.2 \pm 1.3(4.8)^{*}$ & $-55.5 \pm 8.0(14.3)^{k+k+k}$ \\
\hline C & $59 / 36 / 5 / 0$ & $50 / 1 / 6$ & $138 \pm 5(4)$ & $|3| \pm 6(5)$ & $120 \pm 16(13)$ & $-30.6 \pm 3.7(12)$ & $-18.1 \pm 0.4(2.4)^{30.0 \times k}$ & $-11.3 \pm 2.1(18.8)^{3+0 \times 10}$ \\
\hline D & $39 / 57 / 4 / 0$ & $50 / 1 / 6$ & $157 \pm 23(14)$ & $162 \pm 6(4)$ & $110 \pm 16(14)$ & $-34.2 \pm 1.2(3.4)$ & $-26.0 \pm 1.4(5.2)^{k+k k}$ & $-17.2 \pm 0.6(3.4)^{* * k+k}$ \\
\hline E & $59 / 36 / 5 / 0$ & $75 / 1 / 9$ & $124 \pm 8(6)$ & $117 \pm 14(12)$ & $122 \pm 1(I)$ & $-31.8 \pm 2.1(6.7)$ & $-31.8 \pm 2.1(6.7)$ & $-37.5 \pm 2.1(5.6)$ \\
\hline $\mathrm{F}$ & $39 / 57 / 4 / 0$ & $75 / 1 / 9$ & $119 \pm 11(9)$ & $126 \pm 6(5)$ & $128 \pm 5(4)$ & $-29.7 \pm 0.5(1.6)$ & $-27.7 \pm 1.2(4.4)^{* *}$ & 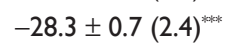 \\
\hline E5 & $54 / 36 / 5 / 5$ & $75 / 1 / 9$ & $140 \pm 5(4)$ & $137 \pm 3(2)$ & $|2| \pm 3(2)^{* *}$ & nd & nd & nd \\
\hline EI5 & $44 / 36 / 5 / 15$ & $75 / 1 / 9$ & $115 \pm 5(4)$ & $118 \pm 4(3)$ & $119 \pm 11(9)$ & $-35.6 \pm 4.9(13.8)$ & $-35.5 \pm 4.0(11.3)$ & $-35.8 \pm 1.4(3.9)$ \\
\hline E30 & $29 / 36 / 5 / 30$ & $75 / 1 / 9$ & $120 \pm 8(7)$ & $129 \pm 7(5)$ & $150 \pm 14(9)^{*}$ & nd & nd & nd \\
\hline
\end{tabular}

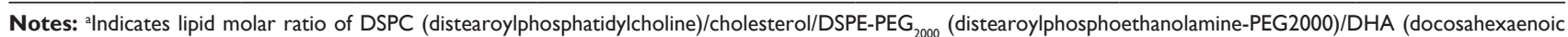
acid); 'indicates (lipid [mg]/ethanol [mL]/dd-water [mL]); ' mean \pm standard deviation (\% coefficient of variation); $* P<0.05 ; * * P<0.01$; $* * * P<0.001$.

Abbreviations: L/E/W, lipid content/ethanol/water; SD, standard deviatio; nd, no detection. 

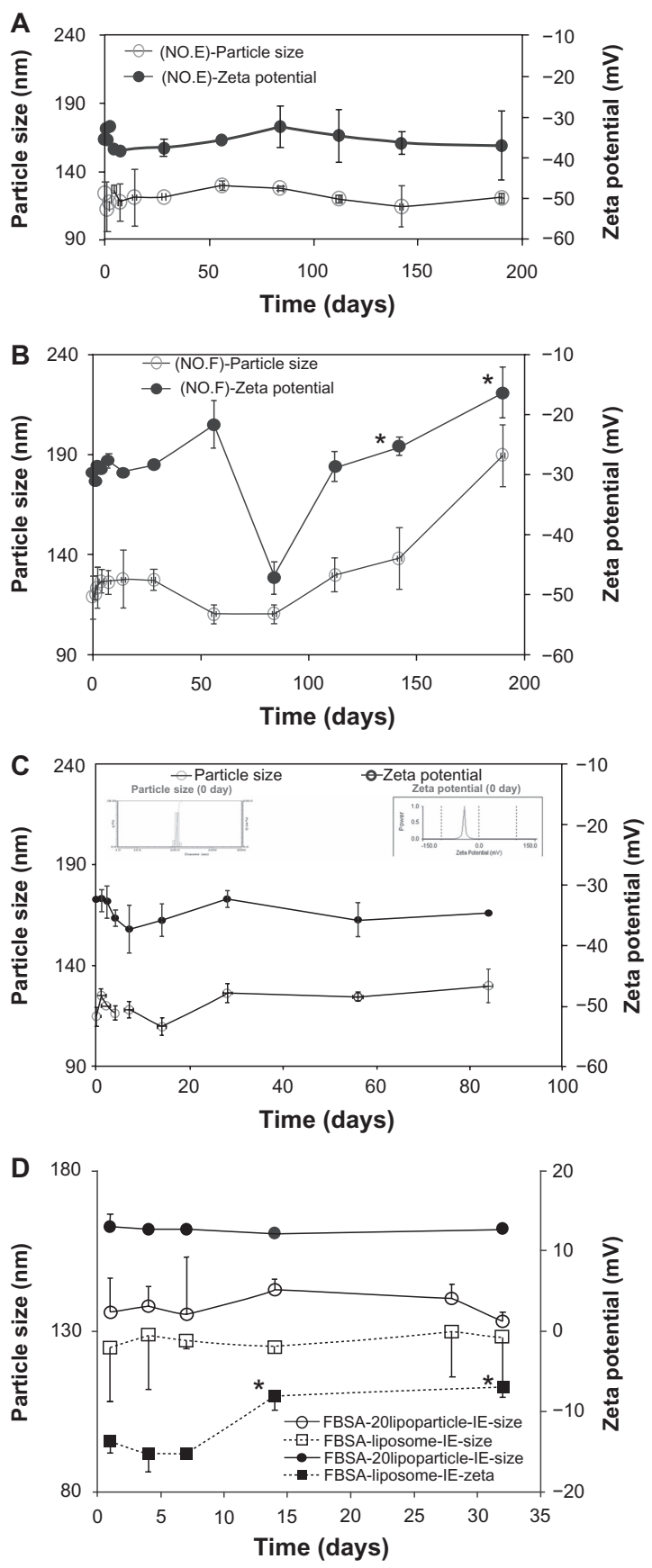

Figure I The mean particle size $(O)$ and zeta potential $(\bullet)$ stability tests for liposome suspensions as a function of time (stored at $4^{\circ} \mathrm{C}$ ). (A) Formula No. E and (B) formula No. F. (C) FITC-BSA-loaded lipoparticles. (D) Comparison of FITC-BSA-loaded liposomes and lipoparticles.

Note: *Compared to 0 day, $P<0.001$ (paired $t$-test) $(\mathrm{n}=3)$.

Abbreviation: FITC-BSA, fluorescein isothiocyanate-conjugated bovine serum albumin.

found that the optimal preparation conditions were as follows: a ratio of DSPC/cholesterol/DSPE-PEG2000/DHA in weight of 44/36/5/15 and a proportion of $\mathrm{L} / \mathrm{E} / \mathrm{W}$ in volume of 75/1/9. Under these conditions, the liposomes had a small particle size and high stability, the mean diameter was $115 \pm 5 \mathrm{~nm}$, and the zeta potential was $-35.6 \pm 4.9$. The liposome size and zeta potential of the E15 formulation remained nearly unchanged over 1 month (Table 1), as no significant differences in size $(2-4 \mathrm{~nm})$ or zeta potential $(0.1-0.3 \mathrm{mV})$ were observed over this period. The E15 suspensions were further assayed for changes in vesicle size over 90 days at $4^{\circ} \mathrm{C}$. The mean particle size and zeta potential from this test are presented in Figure 1C. These results, which we also confirmed via TEM and FE-SEM analysis, demonstrated the high stability of these liposome suspensions.

\section{Preparation and characterization of lipoparticle system}

The effects of FITC-BSA-loaded liposomes and lipoparticles prepared by ethanol injection (I) or the ethanol injection extrusion (IE) on particle size, zeta potential, particle yield, and entrapment efficiency before and after lyophilization are presented in Table 2. It was observed that both FITCBSA-loaded liposomes and lipoparticles prepared by ethanol injection demonstrated a significantly decreased particle size from about $200 \mathrm{~nm}$ to $130 \mathrm{~nm}$. Comparing the optimal stability between liposomes and lipoparticles, it was shown that the lipoparticle formula was more stable than the liposome formula over 30 days, as the zeta potential of liposomes was significantly changed from -13.7 to $-8.6 \mathrm{mV}(P<0.05)$ (Figure 1D). However, the particle size and zeta potential of the lipoparticles were not significantly changed over the 30 days (Figure 1D). Figure 2E shows the typical particle size distribution of lipoparticles after extrusion (FITC-BSAloaded lipoparticle-IE). A very low polydispersity index of less than 0.2 was recorded for all the formulations, indicating a narrow size distribution of vesicles. The vesicle size of the various formulations was recorded to be $215 \pm 2 \mathrm{~nm}(\mathrm{n}=3)$, as calculated using a particle size analyzer, for protamine/ FITC-BSA 20/1 of FITC-BSA-loaded lipoparticles prepared by ethanol injection. The particle size was significantly reduced after passing through a $100 \mathrm{~nm}$ membrane during the ethanol injection method. The vesicle size of the lipoparticles prepared by ethanol injection was recorded to be $134 \pm 9 \mathrm{~nm}$.

The spherical structure of the protamine/FITC-BSA complex (core and lipoparticle) was further confirmed by TEM and FE-SEM analysis (Figure 2B and D). According to the TEM and FE-SEM micrographs, FITC-BSA particles ranged in size from 100 to $130 \mathrm{~nm}$, correlating well with the measurements obtained by the particle size analyzer. The TEM images of the FITC-BSA-liposomes (Figure 2A) and FITC-BSAlipoparticles (Figure 2B) indicated that both the liposomes and lipoparticles were almost spherical and had a smooth 
A TEM of blank liposomes

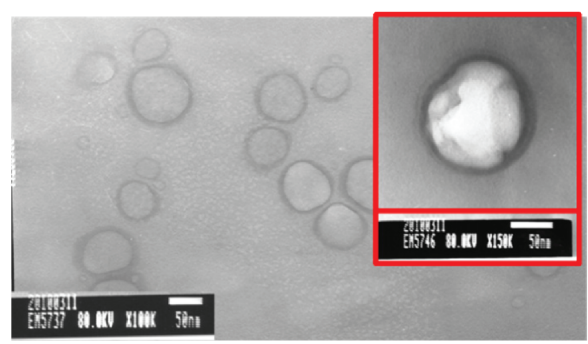

B FITC-BSA-loaded lipoparticles

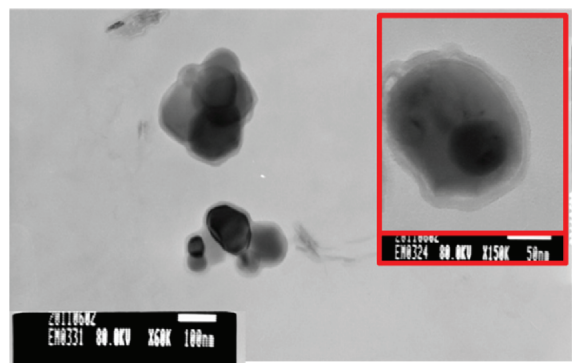

E
C FE-SEM of blank liposomes

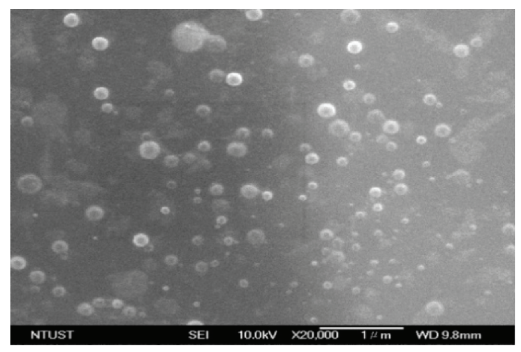

D FITC-BSA-loaded lipoparticles

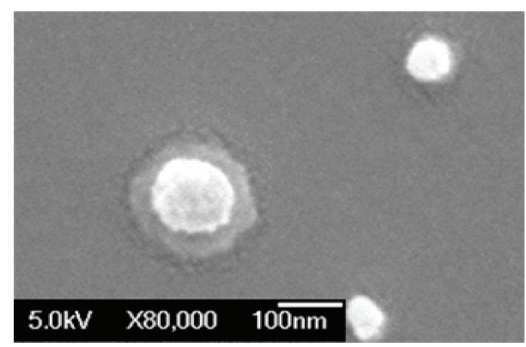

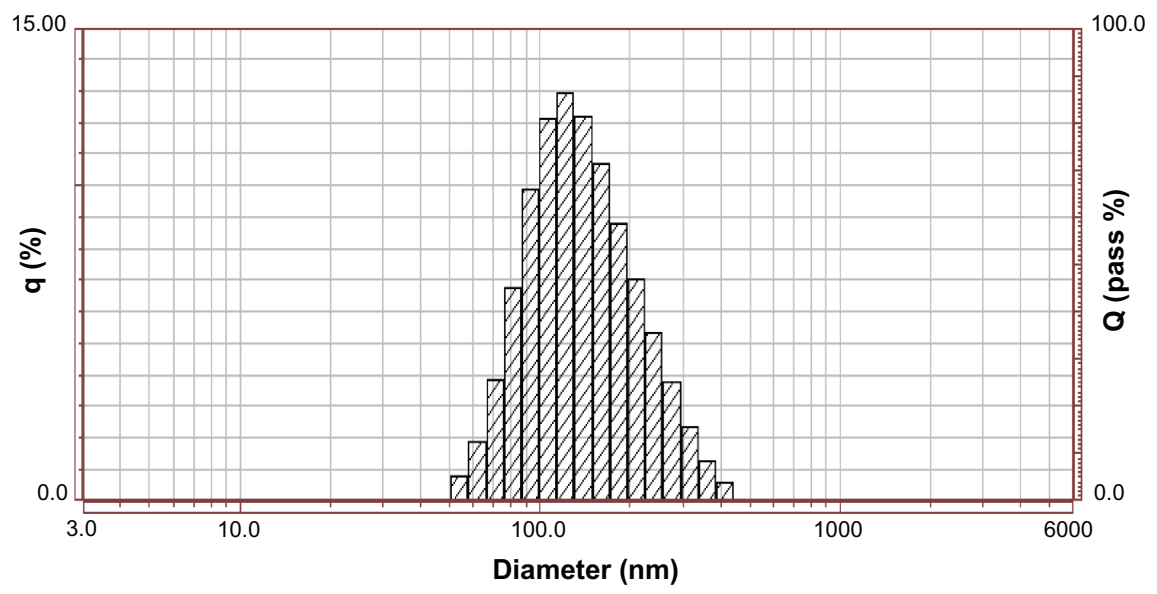

Figure 2 TEM image (left) and FE-SEM image (right) with I\% uranyl acetate negative staining. (A) FITC-BSA-loaded liposomes and (B) FITC-BSA-loaded lipoparticles. (C) FITC-BSA-loaded liposomes and (D) FITC-BSA-loaded lipoparticles. The scale bar is $100 \mathrm{~nm}$. (E) Particle size distribution of FITC-BSA-loaded lipoparticles containing a protamine/FITC-BSA core.

Abbreviations: TEM, transmission electron microscope; FE-SEM, field-emission scanning electron microscope; FITC-BSA, fluorescein isothiocyanate-conjugated bovine serum albumin.

surface. The FE-SEM images of the FITC-BSA-liposomes (Figure 2C) and FITC-BSA-lipoparticles (Figure 2D) revealed nanometric- and quasispherical-shaped particles, respectively. No protein crystals were visible in the TEM or FE-SEM images of the FITC-BSA-loaded liposomes or lipoparticles. Also, no notable differences were found in morphology or size between the liposomes and lipoparticles.

Comparing the FITC-BSA encapsulation efficiency (\%), the FITC-BSA-liposomes prepared by the ethanol injection method had an estimated encapsulation efficiency of $19.0 \% \pm 4.0 \%$, but the encapsulation efficiency for the FITC-BSA-loaded lipoparticles (with a core particle ratio of 20/1) prepared by the ethanol injection method was significantly higher at $48.4 \% \pm 19.7 \%$. Our results showed that using the protamine/ FITC-BSA as a core to prepare lipoparticles significantly increased the encapsulation efficiency by the ethanol injection method. This indicated that FITC-BSA/protamine was effectively entrapped into lipoparticles during formulation. When the same formula and preparation process was used to prepare lipoparticles or liposomes with or without passing through the $100 \mathrm{~nm}$ membrane, it was clear that the use of the extrusion method significantly increased the encapsulation 
efficiency and particle yield, with liposomes demonstrating an increased encapsulation efficiency from $19.0 \%$ to $51.4 \%$ and an increased yield from $69.4 \%$ to $77.4 \%$; the lipoparticles demonstrated an increased encapsulation efficiency from $48.4 \%$ to $59.6 \%$ and an increased yield from $39.0 \%$ to $72.4 \%$. Zeta potential analysis, as shown in Table 2, comparing liposomes with lipoparticles indicated that the zeta potential of liposomes was negative $(-13.7 \mathrm{mV})$ and that of lipoparticles was positive $(13.0 \mathrm{mV})$. As expected, adding positively charged protamine as a core material resulted in positive zeta potentials of the FITC-BSA/protamine complexes as well as the lipoparticles.

It was observed that lyophilization increased the particle size between $8 \%$ and $47 \%$ (Table 2 ). The change in particle size before and after lyophilization was not significantly different between the formulations, with the exception of the blank liposomes prepared by the ethanol injection method and the FITC-BSA-loaded liposomes prepared by the ethanol injection extrusion method. The particle size was shown to be larger when prepared by ethanol injection compared to the ethanol injection extrusion method (17\% vs $10 \%$, respectively), and FITC-BSA-loaded liposomes were larger than lipoparticles (47\% vs 10\%, respectively). After freeze-drying, the particle size and the release profile of the reconstituted lipoparticles did not significantly change over the 4-month storage period compared to that of the freshly prepared lipoparticle suspensions, which indicated that the freeze-drying process increased the stability of the lipoparticles. However, different cryoprotectants and their methods of use need to be investigated to further improve the freeze-drying conditions.

As such, the optimal conditions for the modified ethanol injection extrusion method were as follows: the ratio of DSPC/cholesterol/DSPE-PEG2000/DHA in weight was $44 / 36 / 5 / 15$; the proportion of $\mathrm{L} / \mathrm{E} / \mathrm{W}$ in volume was $75 / 1 / 9$; and the ratio of protamine/FITC-BSA in weight was 20/1. Under these conditions, the lipoparticles had a small particle size and high encapsulation efficiency, their mean diameter was $134 \pm 9 \mathrm{~nm}$, their zeta potential was $13 \pm 1.6$, the yield was $72.4 \%$, and the encapsulation efficiency was $59.6 \%$.

\section{The protein retention profiles of lipoparticles and liposomes}

Protein release was investigated by studying the release of encapsulated FITC-labeled BSA from lipoparticles and comparing it with that of liposomes. Figure 3 illustrates the retention profile of encapsulated FITC-BSA, indicating a prolonged retention time for lipoparticles as compared to liposomes. The effect of lyophilization on the lipoparticle retention profile was not significant, but the freeze-dried liposomes had an obviously reduced ability to retain FITCBSA (A vs C; Figure 3). The initial burst release of FITCBSA was followed by a continued and controlled release

Table 2 The characteristics of FITC-BSA-loaded liposomes and lipoparticles

\begin{tabular}{|c|c|c|c|c|c|c|c|c|c|c|c|}
\hline \multirow[t]{3}{*}{ Formula } & \multicolumn{5}{|c|}{ Particle size( $\mathrm{nm}$ ) } & \multirow{2}{*}{\multicolumn{2}{|c|}{$\begin{array}{l}\text { Zeta potential } \\
(\mathrm{mV})\end{array}$}} & \multirow{2}{*}{\multicolumn{2}{|c|}{ Yield (\%) ${ }^{d}$}} & \multirow{2}{*}{\multicolumn{2}{|c|}{$E E(\%)^{e}$}} \\
\hline & \multicolumn{2}{|c|}{ Before lyo $^{a}$} & \multicolumn{2}{|l|}{ After lyo ${ }^{b}$} & \multirow{2}{*}{$\begin{array}{l}\mathbf{D}^{\mathbf{c}} \\
\%\end{array}$} & & & & & & \\
\hline & Mean $^{f}$ & CV\% ${ }^{\mathrm{g}}$ & Mean & CV\% & & Mean & CV\% & Mean & CV\% & Mean & CV\% \\
\hline Blank liposome-I & $219 \pm 3$ & 2 & $281 \pm 19 *$ & 7 & 25 & $-35.5 \pm 3.9$ & II.I & $90.0 \pm 5.3$ & 6 & - & \\
\hline Blank liposome-IE & $125 \pm 2$ & 19 & $177 \pm\left. 2\right|^{*}$ & 12 & 41 & $-12.4 \pm 1.5$ & 12.0 & $75.6 \pm 10.7$ & 14 & - & \\
\hline FITC-BSA-liposome-I & $202 \pm 5$ & 24 & $218 \pm 10$ & 4 & 8 & $-17.26 \pm 2.9$ & 16.5 & $69.4 \pm 4.7$ & 7 & $19.0 \pm 4.0$ & 20.9 \\
\hline FITC-BSA-liposome-IE & $126 \pm 5$ & 13 & $186 \pm 24^{*}$ & 13 & 47 & $-13.7 \pm 1.4$ & 10.2 & $77.4 \pm 3.2$ & 4 & $51.4 \pm 6.1$ & 11.8 \\
\hline FITC-BSA-lipoparticle-I & $215 \pm 2$ & 31 & $252 \pm 25$ & 10 & 17 & $3.2 \pm 0.4$ & 13.9 & $39.0 \pm 19.9$ & 51 & $48.4 \pm 19.7$ & 40.7 \\
\hline FITC-BSA-lipoparticle-IE & $134 \pm 9$ & 19 & $148 \pm 10$ & 7 & 10 & $13.0 \pm 1.6$ & 12.3 & $72.4 \pm 15.7$ & 22 & $59.6 \pm 0.4$ & 0.7 \\
\hline
\end{tabular}

Notes: ${ }^{a, b}$ Liposomes particle size before/after lyophilization; 'difference in liposome particle size before and after lyophilization,

$$
\begin{gathered}
\mathrm{D} \%=\frac{\Delta\left(\text { lyo }_{\text {befor }}-\mathrm{lyo}_{\text {after }}\right)}{\text { lyo }_{\text {befor }}} \times 100 \% ; \\
{ }^{\mathrm{d}} \mathrm{Yield} \%=\frac{\mathrm{MASS}_{\text {lipo }}}{\mathrm{MASS}_{\text {initial }}} \times 100 \% ; \\
\mathrm{EE} \%=\frac{\left(\mathrm{FITC}-\mathrm{BSA}_{\text {enca }}\right)}{\left(\mathrm{FITC}-\mathrm{BSA}_{\text {total }}\right)} \times 100 \%,
\end{gathered}
$$

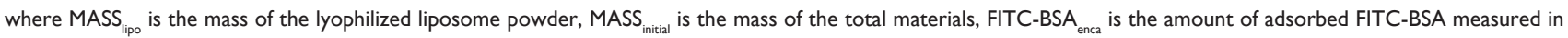
the liposomes; FITC-BSA ${ }_{\text {total }}$ is the initial amount of FITC-BSA, lyo ${ }_{\text {before }}$ is the particle size before lyophilization, lyo after is the particle size after lyophilization; ${ }^{f}$ mean \pm standard deviation, $\mathrm{n}=3 ; \mathrm{s} \%$ coefficient of variation $=\mathrm{SD} /$ mean $\times 100 \%$. *Compared to before lyophilization, $P<0.05$ (paired $t$-test).

Abbreviation: FITC-BSA, fluorescein isothiocyanate-conjugated bovine serum albumin. 
A

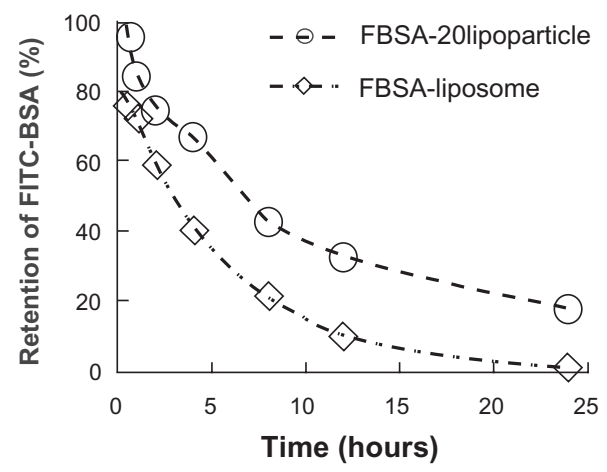

C

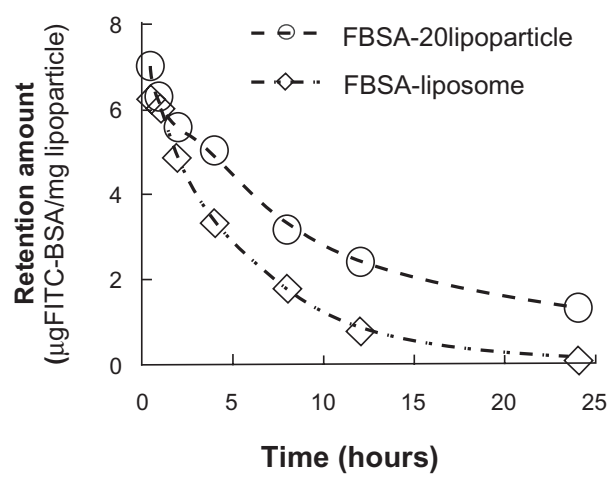

B

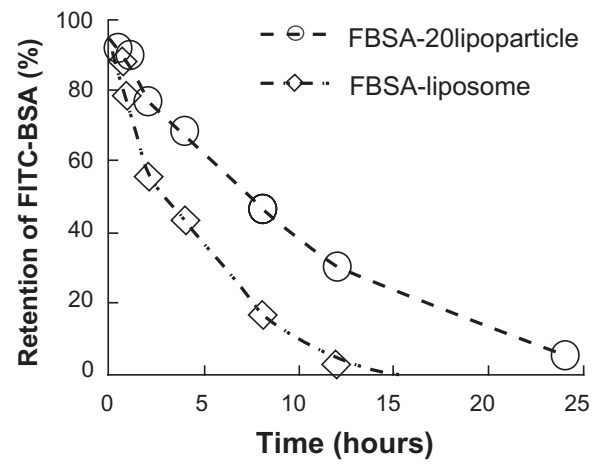

D

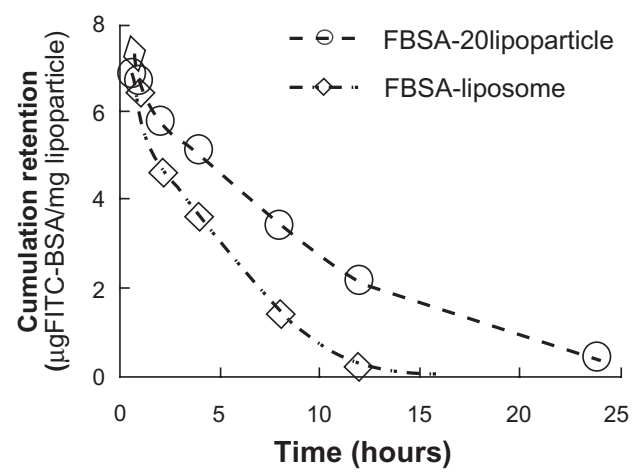

Figure 3 The remaining amount of FITC-BSA from the release profile of FITC-BSA-loaded liposomes and lipoparticles in PBS (pH 7.4) at $37^{\circ} \mathrm{C}$. (A and $\mathbf{C}$ ) Before lyophilization and $(\mathbf{B}$ and $\mathbf{D})$ after lyophilization. FITC-BSA-loaded liposomes $(\diamond)$ and FITC-BSA-loaded lipoparticles containing a protamine/FITC-BSA 20/I core $(\mathrm{O})(\mathrm{n}=3)$. Abbreviations: FITC-BSA, fluorescein isothiocyanate-conjugated bovine serum albumin; PBS, phosphate buffered saline.

phase from both particles up to 1 day. The FITC-BSA burst release of $56.4 \%$ (liposomes) and about 20\% (lipoparticles) was observed within 0.5 hours, and this was followed by a slow and sustained release of $96 \%$ (liposomes) and about $90 \%$ (lipoparticles) by day 1 .

Table 3 presents the in vitro FITC-BSA retention rate constants based on three different mathematical models for FITC-BSA particles. The retention of FITC-BSA in particulate systems involves three different mechanisms: (a) release from the surface of particles (burst release), (b) diffusion through the swollen matrix, and (c) release due to particle erosion. In the majority of cases, drug release from particles follows more than one type of mechanism. The best fitting mathematic model was Higuchi model $\left(R^{2}>0.93\right)$, and the calculated rate constant $\mathrm{k}^{\prime} \mathrm{h}$ was -0.1953 and $-0.1879 \mathrm{hr}-0.5$ for freshly prepared liposomes and lipoparticles, respectively, and 0.2332 and $-0.2172 \mathrm{hr}-0.5$ for freeze-dried liposomes and lipoparticles, respectively. The effect of lyophilization and the time to $50 \%$ release (t50\%) of FITC-BSA-particles calculated by the Higuchi model are shown in Figure 4 . No obvious difference in ( $550 \%$ ) was observed before and after freeze-drying of FITC-BSA particles. However, the (t50\%) of lipoparticles (7.9 hours) was significantly longer than the (t50\%) of liposomes (3.3 hours). This may be attributed to the strong ionic interaction between the counter-ion of FITC-BSA and protamine in the lipoparticles.

Figure 5 shows the SDS-PAGE analysis of protamine/ FITC-BSA particles, FITC-BSA-liposomes, and FITCBSA-lipoparticles before and after lyophilization after 4 and 8 hours of incubation. Bands representing pure as well as extracted antigen at various stages are clearly visible, indicating that the encapsulated FITC-BSA was unaltered. The results suggested that FITC-BSA was successfully encapsulated and remained stable at all stages.

Figure 6 indicates the cytotoxicity of varied concentrations of FITC-BSA-loaded liposomes and lipoparticles against the human epithelial colorectal adenocarcinoma cell line Caco-2, as based on WST-1 analysis. The percentage of 
Table 3 Retention parameters for FITC-BSA-loaded particles obtained after fitting in vitrodrug release data (0.5-24 hours) to three different mathematical models for FITC-BSA retention kinetics

\begin{tabular}{|c|c|c|c|}
\hline \multirow[t]{2}{*}{ Formulation } & \multicolumn{3}{|c|}{$\begin{array}{l}\text { Mathematical models }{ }^{\mathrm{a}} \text { for retention } \\
\text { kinetics }\end{array}$} \\
\hline & Zero order & First order & $\begin{array}{l}\text { Higuchi } \\
\text { model }\end{array}$ \\
\hline \multicolumn{4}{|l|}{ Before lyophilization } \\
\hline FITC-BSA-liposome & $\begin{array}{l}\mathrm{k}_{0}^{\prime}=-0.0319 \\
\mathrm{R}^{2}=0.7838\end{array}$ & $\begin{array}{l}k_{1}^{\prime}=-0.0556 \\
R^{2}=0.6688\end{array}$ & $\begin{array}{l}\mathrm{k}_{\mathrm{h}}^{\prime}=-0.1953 \\
\mathrm{R}^{2}=0.9307\end{array}$ \\
\hline FITC-BSA lipoparticle & $\begin{array}{l}k_{0}^{\prime}=-0.03 I 4 \\
R^{2}=0.8543\end{array}$ & $\begin{array}{l}\mathrm{k}_{1}^{\prime}=-0.0882 \\
\mathrm{R}^{2}=0.5940\end{array}$ & $\begin{array}{l}k_{h}^{\prime}=-0.1879 \\
R^{2}=0.9669\end{array}$ \\
\hline \multicolumn{4}{|l|}{ After lyophilization } \\
\hline FITC-BSA-liposome & $\begin{array}{l}\mathrm{k}_{0}^{\prime}=-0.0377 \\
\mathrm{R}^{2}=0.7580\end{array}$ & $\begin{array}{l}\mathrm{k}_{1}^{\prime}=-0.0735 \\
\mathrm{R}^{2}=0.5584\end{array}$ & $\begin{array}{l}\mathrm{k}_{\mathrm{h}}^{\prime}=-0.2332 \\
\mathrm{R}^{2}=0.9154\end{array}$ \\
\hline FITC-BSA lipoparticle & $\begin{array}{l}k_{0}^{\prime}=-0.0374 \\
R^{2}=0.9306\end{array}$ & $\begin{array}{l}\mathrm{k}_{1}^{\prime}=-0.0965 \\
\mathrm{R}^{2}=0.7183\end{array}$ & $\begin{array}{l}k_{h}^{\prime}=-0.2172 \\
R^{2}=0.9922\end{array}$ \\
\hline
\end{tabular}

Notes: ${ }^{2}$ Zero order, $M_{t} / M_{+}=k_{0}^{\prime} t$; first order, $M_{t} / M_{\perp}=1-\exp \left(-k^{\prime}, t\right)$; higuchi model, $M_{t} / M_{\perp}=k_{h}^{\prime} t^{1 / 2}$, where $M_{t} / M_{\perp}$ is the fraction of the drug retained at time $t$ and $k_{0}^{\prime}, k^{\prime}$, and $\mathrm{k}_{\mathrm{h}}^{\prime}$, represent the zero-order release constant, first-order retention constant, and Higuchi constant, respectively.

Abbreviation: FITC-BSA, fluorescein isothiocyanate-conjugated bovine serum albumin.

viable cells was greater than $85 \%$ after treatment with FITCBSA-loaded liposomes and greater than $95 \%$ after treatment with FITC-BSA-loaded lipoparticles at concentrations of $0.25,0.025$, and $0.0025 \mathrm{mg} / \mathrm{mL}$. The higher percentage of cell viability relative to controls at these concentrations indicated that the FITC-BSA-loaded particles were not cytotoxic towards Caco-2 cells under these conditions. It should be noted that under the conditions used, no aggregation of particles was observed.

The FITC-BSA-loaded particles were endocytosed efficiently (Figure 7). A total of $200 \mu \mathrm{L}$ of suspension of different formulations $(0.01 \mathrm{mg} / \mathrm{mL})$ was added to Caco-2 cells.

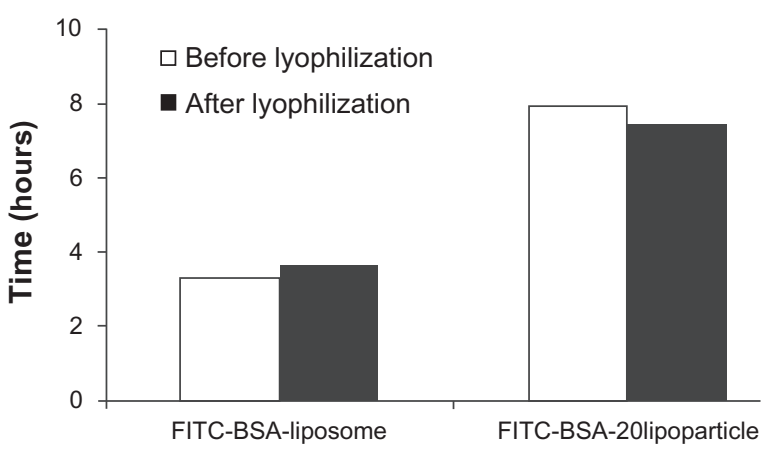

Figure 4 The $50 \%$ retention time $\left(t_{50 \%}\right)$ of FITC-BSA (before [white] and after [black] lyophilization) of the various formulations.

Notes: The results were calculated using the Higuchi equation. $* P<0.01$.

Abbreviation: FITC-BSA, fluorescein isothiocyanate-conjugated bovine serum albumin.
The cells were then harvested and analyzed for FITC-BSA uptake by flow cytometer analysis in order to investigate retention/absorption and to provide further information on the cellular response to particle incubation. The control cells were evenly spread and maintained their typical shape and surface morphology. The test cells were found to absorb the nanoparticles to an acceptable extent. For all particles, after 1 hour of incubation, the cells presented with brightly dotted fluorescence within the membrane of viable cells; this was retained for up to 6 hours. At 1 hour, the uptake of FITC-BSA was significantly greater $(12$-fold; $P<0.01$ ) for the FITC-BSA-loaded lipoparticles than the FITC-BSAloaded liposomes (Figure 7), indicating that lipoparticles 100-200 nm in size acquire the best properties for cellular uptake. The distribution of fluorescence in the cytoplasm of Caco-2 cells may be partly due to the high level of FITCBSA released from the lipoparticles. These results indicate that the lipoparticles were endocytosed into the cells and that the FITC-BSA-loaded lipoparticles had increased penetration into Caco-2 cells relative to the liposomes.

\section{Discussion}

The aim of this study was to develop a novel preparation strategy for liposomes for use as carriers for the delivery of macromolecules. The preparation strategy was based on the principles of the ethanol-injection method and used a membrane contactor optimized for liposome production. There were many factors affecting the particle size of liposomes. In all the experiments (Table 1), the dispersed phase (ie, phospholipids and cholesterol in ethanol) passed very quickly through the membrane (5-10 seconds). In this work, the flux was not measured vs time; thus, no exact fouling data were available. However, the very high average fluxes, combined with the fact that the phospholipid concentrations had no effect on the experiment duration, suggested that fouling was probably very low for these experimental conditions. This might be explained by the relatively low concentration of phospholipids in the dispersed phase and the mean membrane pore size, which was, in all cases, less than $150 \mathrm{~nm}$. The experiment using the $100 \mathrm{~nm}$ membrane and a phospholipid concentration of $0.15 \mathrm{mM}$ was repeated ten times in order to study the reproducibility of this technique. The pressure of the organic phase, the volume of both phases, as well as the aqueous phase flow rate were kept constant. In our study, the preparation methods had a greater influence on particle size than the formulation of the liposomes. A similar result was reported by Elbayoumi et al ${ }^{18}$ using lipid film hydration to prepare liposomes, which were extruded through $200 \mathrm{~nm}$ and 


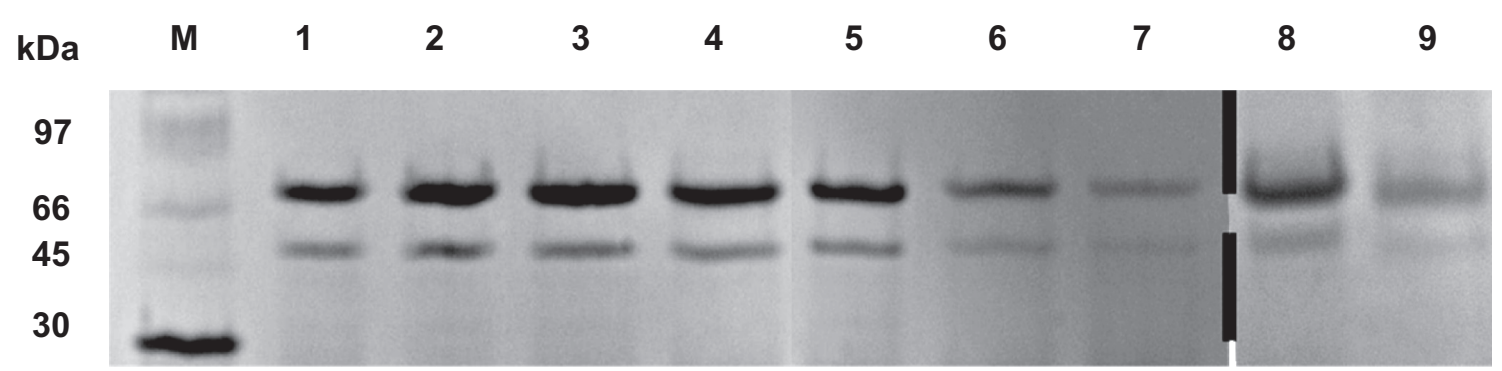

Figure 5 Protein stability evaluation by SDS-PAGE (M, molecular weight markers; I, BSA; 2, FITC-BSA; 3, FITC-BSA particle; 4, FITC-BSA liposome; 5, FITC-BSA lipoparticle-I; 6, FITC-BSA lipoparticle-IE; 7, Freeze-dried FITC-BSA lipoparticle-IE; 8, FITC-BSA lipoparticle-IE in I3.7 mM PBS for 4 hours; and 9, FITC-BSA lipoparticle-IE in I3.7 mM PBS for 8 hours).

Abbreviations: SDS-PAGE, sodium dodecyl sulfate polyacrylamide gel electrophoresis; FITC-BSA, fluorescein isothiocyanate-conjugated bovine serum albumin.

then $100 \mathrm{~nm}$ pore-size nucleopore polycarbonate membranes to obtain uniform vesicles of about $130 \mathrm{~nm}$ in size.

Eckert et $\mathrm{al}^{28}$ reported that liposomal DHA is able to restore or maintain physiological membrane properties, which are required for neuroprotective sAPP $\alpha$ secretion and autocrine modulation for neuronal survival. Polyunsaturated fatty acids (PUFA) are essential for regulating the fluidity of cell membranes, and there are several lines of evidence that this fluidity is important for the modulation of amyloid precursor protein processing. In the present study, we added DHA in the formulation, which represents the most abundant PUFA in the brain and is implicated in various functions, including mediation of membrane-protein interactions, gene expression, neurogenesis, and learning.

When encapsulating the hydrophilic proteins into the liposomes, only $19 \%$ of the FITC-BSA was entrapped in the liposome suspension. In an effort to overcome the limitation of encapsulation efficiency, instability, and early release of entrapped bioactive proteins from liposomes, we designed and tested lipoparticles. Lipoparticles are advanced liposomal constructs bearing a core of biocompatible protamine

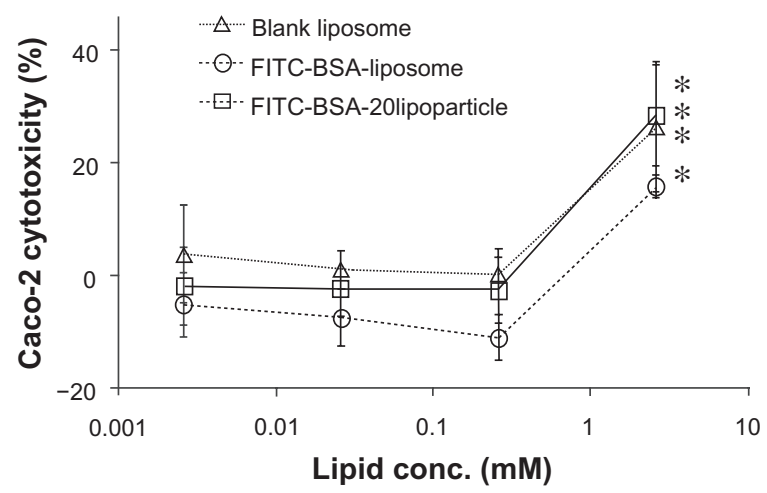

Figure 6 Cytotoxicity profile containing a protamine/FITC-BSA core ( $\square$ ) after a 72-hour incubation with Caco-2 cell, as determined by WST-I assay. Percent viability of fibroblasts is expressed relative to control cells $(n=6)$.

Abbreviation: FITC-BSA, fluorescein isothiocyanate-conjugated bovine serum albumin. with FITC-BSA, which serves as a functional skeleton and provides mechanical support for the lipid vesicle. A high efficiency of encapsulation of FITC-BSA into lipoparticles (59.7\%) was obtained by preparing protamine-containing FITC-BSA nanoparticles entrapped in phospholipids. This high encapsulation efficiency of FITC-BSA into lipoparticles was believed to be due to the solid core containing protamine/ FITC-BSA and, therefore, to the increased coating ability of the phospholipids. Protamine, which has been shown to extend the release period of the chelate both in vitro and in vivo with protein in regular clinical use, was used for the design of novel membrane-translocating/nuclear-localizing pharmaceuticals whose development was initiated with other membrane-translocating peptides. ${ }^{29,30}$ In addition, the protamine in solid lipid nanoparticles is a biodegradable particulate drug delivery system. Only a few investigations have studied the incorporation of proteins into lipoparticles and little research has been reported on drug release from proteinloaded lipoparticles. As expected, the release of protein from lipoparticle systems was slower than from liposomes only. In the lipoparticle system, a very small burst release (from the surface of the particles) of about $20 \%$ was observed within 0.5 hours, and then slow and sustained release of about $90 \%$ was observed at 24 hours (diffusion through the swollen rubbery matrix, and release due to polymer erosion). This may be attributed to the strong ionic interaction between the counter-ion of FITC-BSA and protamine. The core polymer structure made the lipoparticle more stable and promoted continued and controlled release via diffusion release and/ or swelling release. The liposome system showed a $56.4 \%$ initial burst at 0.5 hours. The higher level of burst release from liposomes may be due to the decreased concentration of positively charged groups, which causes the ionic interaction between the counter-ion of FITC-BSA and the lipid to weaken. To examine the mechanism of drug release from our formulation, we analyzed three different kinetic models. 

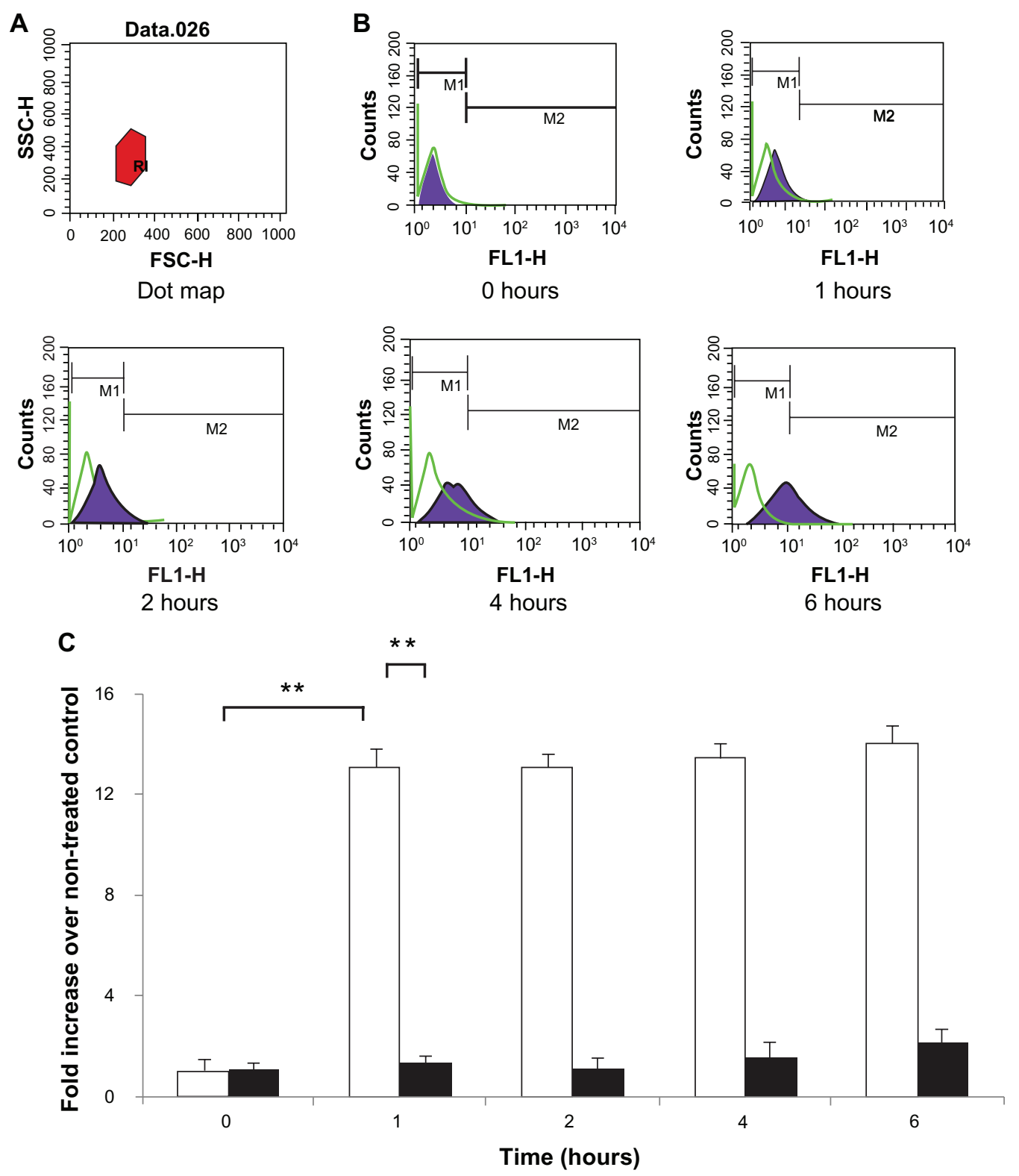

Figure 7 Caco-2 cell uptake profiles of FITC-BSA-loaded lipoparticles (blank) and liposomes (black). Data represents mean \pm SD, $n=3$. (A) Forward and side light scatter was used to gate the desired scattering events (normal cells) from dead cells and cell debris. (B) Uptake of FITC-BSA-loaded PEGylated liposomes and lipoparticles into Caco-2 cells. Cells were analyzed with $488 \mathrm{~nm}$ excitation and $522 \mathrm{~nm}$ band-pass filters in the emission path. (C) Fluorescence intensity of FITC-BSA-loaded liposome and lipoparticle preparations in normal cells expressed as the intensity ratio by dividing by the untreated control.

Notes: Data are expressed as mean $\pm \mathrm{SD}, \mathrm{n}=3$ (student's $t$-test; $* * P<0.0 \mathrm{I}$ ).

Abbreviations: FITC-BSA, fluorescein isothiocyanate-conjugated bovine serum albumin; SD, standard deviation.

In PBS solution, the Higuchi model was the best fit with the release kinetics data for FITC-BSA from liposome and lipoparticles, respectively. It seems that the process of FITCBSA release is mainly controlled by the diffusion process. Further research along these lines might be useful to further our understanding of this important pharmaceutical.

Recently, particular emphasis has been placed on the measures that protect membrane integrity during lyophilization. Lyoprotective mechanisms, such as water replacement and vitrification models, have been known for the past few decades and are well recognized. These measures mainly focus on the protection of the lipid bilayers from damage by ice crystals during freezing, inhibition of vesicle fusion/ aggregation following dehydration, and the avoidance of a phase transition during rehydration. These problems are closely related to the choice of formulation and technological parameters during lyophilization. More importantly, the choice of less than optimal parameters will result in failure of the final freeze-dried cakes. Hence, many factors affecting these above processes, such as the selection of lyoprotectants, 
liposome bilayer composition, and freeze-drying protocols, need to be optimized. ${ }^{22}$ The particle size of the reconstituted liposomes or lipoparticles were also affected by many factors, such as the cryoprotectant, freeze-drying time, particle size of the freshly made liposomes, and other characteristics, of which the cryoprotectant is considered one of the most crucial factors. Christensen et $\mathrm{al}^{23}$ compared the cryoprotective effects of trehalose and sucrose on DDA/TDB liposomes and reported that trehalose was a more efficient stabilizer than sucrose. In our study, the results showed that when trehalose was used as a cryoprotectant, the lipoparticles had a better response than liposomes.

The physicochemical properties of liposomes including size, charge, and release profile are the governing factors of stability. Storage stability of various liposomal formulations was evaluated at two different dosages, for both suspensions and lyophilized powder, at $4^{\circ} \mathrm{C} \pm 1^{\circ} \mathrm{C}$ and $25^{\circ} \mathrm{C} \pm 1^{\circ} \mathrm{C}$. For lyophilized powder stored at $4{ }^{\circ} \mathrm{C} \pm 1{ }^{\circ} \mathrm{C}$ for 90 days, $26 \%$ FITC-BSA leakage was detected from conventional liposomes while about $5 \%$ leakage was found for lipoparticles, indicating the higher in vitro stability of lipoparticles. Furthermore no change in lamellarity and no significant difference in vesicular size were observed following lipoparticle storage. Following SDS-PAGE analysis, clearly visible bands of pure as well as extracted antigen at various time intervals were obtained, showing that the encapsulated FITC-BSA protein was unaltered for up to 90 days. These results suggested that FITC-BSA was successfully encapsulated and remained stable at $4^{\circ} \mathrm{C} \pm 1^{\circ} \mathrm{C}$ for 90 days. The freshly made liposome and lipoparticle suspensions and the freeze-dried liposomes and lipoparticles demonstrated highly stable properties when stored away from light at $4^{\circ} \mathrm{C}$. As we expected, lipoparticles were stable after lyophilization with all of the advantages of liposomes, while eliminating the instability of liposomes, and with the added advantage of controlled release over a prolonged period of time. This indicates a good opportunity for their commercial use as delivery vehicles for recombinant proteins, monoclonal antibody, or nucleic acid-based products.

In order to study the cellular uptake of nanoparticles in vitro and in vivo, the use of fluorescently labeled nanoparticles is the most common experimental approach. ${ }^{31}$ Due to its similar structural and functional differentiation to mature enterocytes, the Caco- 2 monolayer model is an established in vitro tool for evaluating the intestinal permeability and metabolism of drugs. ${ }^{27}$ FITC-BSA makes cellular uptake of nanoparticles readily detectable by fluorescence microscopy. ${ }^{26}$ The extent of particle uptake was determined by flow cytometry and quantitative extraction of the markers from the cells. It has been proposed that the size of the particles plays a key role in their adhesion to and interaction with living cells. ${ }^{32}$ In general, it is assumed that particles up to about 100-200 $\mathrm{nm}$ can be internalized by receptor-mediated endocytosis, while larger particles have to be taken up by phagocytosis. ${ }^{33}$ The smaller-sized particles seem to have more efficient interfacial interactions with the cell membrane compared to larger-sized particles. ${ }^{27}$ Therapeutic use of lipoparticles is of importance, since the small size of lipoparticles could improve efficacy of particle-based oral drug delivery systems and the smaller size could also improve the efficiency of cellular uptake, making these particles highly feasible for use in oral drug delivery therapy.

\section{Conclusion}

This study demonstrated that spherical and mono dispersions of FITC-BSA-loaded PEG-modified lipoparticles can be prepared by an ethanol injection extrusion method with spontaneous assembly, with protamine and FITCBSA as the protein core and a lipid formula containing distearoyl phosphatidylcholine/cholesterol/distearoyl phosphoethanolamine-PEG2000/docosahexaenoic acid. The PEG-modified lipoparticles demonstrated an average particle size of $133.7 \pm 8.6 \mathrm{~nm}$ with a positive zeta potential of $13.3 \mathrm{mV}$. The storage stability assays and SDS-PAGE results confirmed that the preparation process and products were still satisfactory for as long as 90 days. A high encapsulation efficiency $(59.7 \%)$ of FITC-BSA was achieved, and the release profile of FITC-BSA from the lipoparticles indicated a small burst release followed by a continued and controlled release. The protein retention of the lipoparticles was twice as long as that of liposomes. The cytotoxicity and cellular uptake assays indicated that the PEG-modified lipoparticles were less toxic to cells and were more efficient at delivery into the cells than liposomes. In conclusion, this new lipoparticle system offers interesting potential as a carrier for proteins and hydrophilic compounds.

\section{Acknowledgment}

Financial support for this work was provided by the National Science Council (NSC 98-2320-B-016-003-MY3).

\section{Disclosure}

The authors report no conflicts of interest in this work. 


\section{References}

1. Cai S, Yang Q, Bagby TR, Forrest ML. Lymphatic drug delivery using engineered liposomes and solid lipid nanoparticles. Adv Drug Deliv Rev. 2011;63(10-11):901-908.

2. Muller RH, Keck CM. Challenges and solutions for the delivery of biotech drugs - a review of drug nanocrystal technology and lipid nanoparticles. J Biotechnol. 2004;113(1-3):151-170.

3. Tan ML, Choong PFM, Dass CR. Recent developments in liposomes, microparticles and nanoparticles for protein and peptide drug delivery. Peptides. 2010;31(1):184-193.

4. Mufamadi MS, Pillay V, Choonara YE, et al. A review on composite liposomal technologies for specialized drug delivery. J Drug Deliv. 2011;2011:939851.

5. Abu Lila A, Ishida T, Kiwada H. Targeting anticancer drugs to tumor vasculature using cationic liposomes. Pharmaceutical Research. 2010; 27(7):1171-1183.

6. Patel NR, Rathi A, Mongayt D, Torchilin VP. Reversal of multidrug resistance by co-delivery of tariquidar (XR9576) and paclitaxel using long-circulating liposomes. Int J Pharm. 2011;416(1):296-299.

7. Kaasgaard T, Andresen T. Liposomal cancer therapy: exploiting tumor characteristics. Expert Opin Drug Deliv. 2010;7(2):225-243.

8. Wong HL, Chattopadhyay N, Wu XY, Bendayan R. Nanotechnology applications for improved delivery of antiretroviral drugs to the brain. Advanced Drug Delivery Reviews. 2010;62(4-5):503-517.

9. Wang Z, Wang L, Zhang J, Li Y, Zhang D. A study on the preparation and characterization of plasmid DNA and drug-containing magnetic nanoliposomes for the treatment of tumors. Int $J$ Nanomedicine. 2011;6:871-875.

10. Tiwari S, Goyal A, Khatri K, Mishra N, Vyas S. Gel core liposomes: an advanced carrier for improved vaccine delivery. $J$ Microencapsul. 2009;26(1):75-82.

11. Thevenot J, Troutier A-L, David L, Delair T, Ladavière C. Steric stabilization of lipid/polymer particle assemblies by poly(ethylene glycol)-lipids. Biomacromolecules. 2007;8(11):3651-3660.

12. Gjetting T, Arildsen N, Christensen $\mathrm{C}$, et al. In vitro and in vivo effects of polyethylene glycol (PEG)-modified lipid in DOTAP/cholesterolmediated gene transfection. Int J Nanomedicine. 2010;5:371-383.

13. Crosasso P, Ceruti M, Brusa P, Arpicco S, Dosio F, Cattel L. Preparation, characterization and properties of sterically stabilized paclitaxelcontaining liposomes. J Control Release. 2000;63(1-2):19-30.

14. Yang T, Cui F-D, Choi M-K, et al. Enhanced solubility and stability of PEGylated liposomal paclitaxel: In vitro and in vivo evaluation. Int $J$ Pharm. 2007;338(1-2):317-326.

15. Liu C, Yang S, Liu W, Wang R, Wan J, Liu W. Preparation and characterization of medium-chain fatty acid liposomes by lyophilization. J Liposome Res. 2010;20(3):183-190.

16. Liu W, Liu WL, Liu CM, et al. Medium-chain fatty acid nanoliposomes for easy energy supply. Nutrition. 2011;27(6):700-706.

17. Toriyabe N, Hayashi Y, Hyodo M, Harashima H. Synthesis and evaluation of stearylated hyaluronic acid for the active delivery of liposomes to liver endothelial cells. Biol Pharm Bull. 2011;34(7):1084-1089.
18. Elbayoumi TA, Pabba S, Roby A, Torchilin VP. Antinucleosome antibody-modified liposomes and lipid-core micelles for tumor-targeted delivery of therapeutic and diagnostic agents. J Liposome Res. 2007; 17(1):1-14.

19. Domazou A, Luisi P. Size distribution of spontaneously formed liposomes by the alcohol injection method. J Liposome Res. 2002;12(3): 205-220.

20. Maitani Y, Igarashi S, Sato M, Hattori Y. Cationic liposome (DC-Chol/DOPE = 1:2) and a modified ethanol injection method to prepare liposomes, increased gene expression. Int J Pharm. 2007;342(1-2): 33-39.

21. Ducat E, Brion M, Lecomte F, Evrard B, Piel G. The experimental design as practical approach to develop and optimize a formulation of peptideloaded liposomes. AAPS PharmSciTech. 2010;11(2):966-975.

22. Chen C, Han D, Cai C, Tang X. An overview of liposome lyophilization and its future potential. J Control Release. 2010;142(3):299-311.

23. Christensen D, Kirby D, Foged C, et al. Alpha,alpha'-trehalose 6,6'-dibehenate in non-phospholipid-based liposomes enables direct interaction with trehalose, offering stability during freeze-drying. Biochim Biophys Acta. 2008;1778(5):1365-1373.

24. Panwar P, Pandey B, Lakhera P, Singh K. Preparation, characterization, and in vitro release study of albendazole-encapsulated nanosize liposomes. Int J Nanomedicine. 2010;5:101-108.

25. Higuchi T. Mechanism of sustained-action medication. Theoretical analysis of rate if release of solid drugs dispersed in solid matrices. J Pharm Sci. 1963;52:1145-1149.

26. Yeh M-K, Cheng K-M, Hu C-S, Huang Y-C, Young J-J. Novel proteinloaded chondroitin sulfate-chitosan nanoparticles: Preparation and characterization. Acta Biomater. 2011;7(10):3804-3812.

27. Win KY, Feng SS. Effects of particle size and surface coating on cellular uptake of polymeric nanoparticles for oral delivery of anticancer drugs. Biomaterials. 2005;26(15):2713-2722.

28. Eckert GP, Chang S, Eckmann J, et al. Liposome-incorporated DHA increases neuronal survival by enhancing non-amyloidogenic APP processing. Biochim Biophys Acta. 2011;1808(1):236-243.

29. Reynolds F, Weissleder R, Josephson L. Protamine as an Efficient Membrane-Translocating Peptide. Bioconjug Chem. 2005;16(5): 1240-1245.

30. Jiang Y, Shi K, Xia D, et al. Protamine modified metal ion-protein chelate microparticles for sustained release of interferon. Int J Pharm. 2011;407(1-2):31-37.

31. Yee S. In vitro permeability across caco-2 cells (colonic) can predict in vivo (small intestinal) absorption in man - fact or myth. Pharm Res. 1997;14(6):763-766.

32. Foster K, Yazdanian M, Audus K. Microparticulate uptake mechanisms of in-vitro cell culture models of the respiratory epithelium. J Pharm Pharmacol. 2001;53(1):57-66.

33. Couvreur P, Puisieux F. Nano- and microparticles for the delivery of polypeptides and proteins. Adv Drug Deliv Rev. 1993;10(2-3): $141-162$.
International Journal of Nanomedicine

\section{Publish your work in this journal}

The International Journal of Nanomedicine is an international, peerreviewed journal focusing on the application of nanotechnology in diagnostics, therapeutics, and drug delivery systems throughout the biomedical field. This journal is indexed on PubMed Central, MedLine, CAS, SciSearch $®$, Current Contents $₫ /$ Clinical Medicine,

\section{Dovepress}

Journal Citation Reports/Science Edition, EMBase, Scopus and the Elsevier Bibliographic databases. The manuscript management system is completely online and includes a very quick and fair peer-review system, which is all easy to use. Visit http://www.dovepress.com/ testimonials.php to read real quotes from published authors. 